\title{
Risk factors and incidence over time for lower extremity amputations in people with type 1 diabetes: an observational cohort study of 46,088 patients from the Swedish National Diabetes Registry
}

\author{
Sara Hallström ${ }^{1,2}$ (D) Ann-Marie Svensson ${ }^{2,3}$ (D) Aldina Pivodic $^{4,5}$ (D) Arndís F. Ólafsdóttir $^{2,6}$ (D) \\ Magnus Löndahl $^{7,8}$ (D) $\cdot$ Hans Wedel $^{9}$ (D) $\cdot$ Marcus Lind $^{2,6}$ (D)
}

Received: 6 February 2021 / Accepted: 14 June 2021 / Published online: 8 September 2021

(C) The Author(s) 2021

\begin{abstract}
Aims/hypothesis The aim of this work was to study the incidence over time of lower extremity amputations and determine variables associated with increased risk of amputations in people with type 1 diabetes.

Methods Individuals with type 1 diabetes registered in the Swedish National Diabetes Registry with no previous amputation from 1 January 1998 and followed to 2 October 2019 were included. Time-updated Cox regression and gradient of risk per SD were used to evaluate the impact of risk factors on the incidence of amputation. Age- and sex-adjusted incidences were estimated over time.

Results Of 46,088 people with type 1 diabetes with no previous amputation (mean age 32.5 years [SD 14.5], 25,354 [55\%] male sex), 1519 (3.3\%) underwent amputation. Median follow-up was 12.4 years. The standardised incidence for any amputation in 1998-2001 was 2.84 (95\% CI 2.32, 3.36) per 1000 person-years and decreased to 1.64 (95\% CI 1.38, 1.90) per 1000 personyears in 2017-2019. The incidence for minor and major amputations showed a similar pattern. Hyperglycaemia and renal dysfunction were the strongest risk factors for amputation, followed by older age, male sex, cardiovascular comorbidities, smoking and hypertension. Glycaemic control and age- and sex-adjusted renal function improved during the corresponding time period as amputations decreased.

Conclusions/interpretation The incidence of amputation and of the most prominent risk factors for amputation, including renal dysfunction and hyperglycaemia, has improved considerably during recent years for people with type 1 diabetes. This finding has important implications for quality of life, health economics and prognosis regarding CVD, indicating a trend shift in the treatment of type 1 diabetes.
\end{abstract}

Keywords Amputation - Cardiovascular disease $\cdot$ Epidemiology $\cdot \mathrm{HbA}_{1 \mathrm{c}} \cdot$ Lower-extremity amputation $\cdot$ Risk factors $\cdot$ Type 1 diabetes

Sara Hallström

sara.el.nilsson@vgregion.se

1 Department of Internal Medicine, Sahlgrenska University Hospital, Gothenburg, Sweden

2 Department of Molecular and Clinical Medicine, University of Gothenburg, Gothenburg, Sweden

3 Center of Registers in Region Västra Götaland, Gothenburg, Sweden

4 Department of Clinical Neuroscience, Institute of Neuroscience and Physiology, Sahlgrenska Academy, University of Gothenburg, Gothenburg, Sweden
5 Statistiska Konsultgruppen, Gothenburg, Sweden

6 Department of Medicine, NU-Hospital Group, Uddevalla, Sweden

7 Department of Clinical Sciences Lund, Faculty of Medicine, Lund University, Lund, Sweden

8 Department of Endocrinology, Skane University Hospital, Lund, Sweden

9 Department of Health Metrics, Sahlgrenska Academy, University of Gothenburg, Gothenburg, Sweden 


\section{Research in context}

\section{What is already known about this subject?}

- Most studies estimating incidence of amputations include all people with diabetes or subpopulations at very high risk of amputations, such as those with established ulcers or peripheral vascular disease

- A recent study including data until 2013 showed a 40-fold excess risk for amputation in individuals with type 1 diabetes compared with those without diabetes

- There are limited recent data on the incidence of and risk factors for amputations in people with type 1 diabetes

\section{What is the key question?}

- Are there any changes in incidence over time and what are the risk factors for lower extremity amputation in people with type 1 diabetes?

\section{What are the new findings?}

- In this population-based study of 46,088 people with type 1 diabetes we found reduced incidence over time of lower extremity amputations and an improved risk factor burden including renal complications and hyperglycaemia

- Renal dysfunction, hyperglycaemia, older age, male sex, cardiovascular comorbidities, smoking and hypertension were shown to be risk factors for amputations in people with type 1 diabetes

\section{How might this impact on clinical practice in the foreseeable future?}

- Modern diabetes treatment has probably decreased risk factor burden and will possibly continue to improve prognosis for the risk of amputations in people with type 1 diabetes over time

\begin{tabular}{ll}
\multicolumn{2}{l}{ Abbreviations } \\
DBP & Diastolic BP \\
LEA & Lower extremity amputation \\
NDR & National Diabetes Register \\
NPR & National Patient Register \\
SBP & Systolic BP
\end{tabular}

\section{Introduction}

Diabetes foot ulcers are common, healing is often delayed and limb loss through amputation is a not infrequent final outcome [1]. Lower extremity amputation (LEA) in people with diabetes is a major source of disability and distress and constitutes a significant financial burden for the healthcare system [2-4]. About half of all non-traumatic amputations in the western world are attributable to diabetes, and an earlier study showed a 40-fold excess risk of amputations in people with type 1 diabetes compared with the general population [5].

There are multiple pathways to diabetic foot ulceration but the contributions of micro- and macrovascular disease are prominent $[6,7]$. Thus, risk factors for these conditions, such as hyperglycaemia, hypertension and hyperlipidaemia, could be related to LEA in type 1 diabetes $[1,6]$. Changes in this risk factor burden, improved diabetic foot ulcer care following the introduction of multidisciplinary teams, and extended use of revascularisation have possibly reduced the rate of LEA [8-10].

The risk of LEA has mostly been studied in populations with type 2 diabetes or in mixed groups of individuals with diabetes and findings suggest that LEA is associated with older age, male sex, renal dysfunction and worse glycaemic control [11-16]. Recent studies on incidence and a wide range of risk factors are scarcer in people with type 1 diabetes.

The aim of this study was to investigate incidence over time and potential risk factors, including age, sex, diabetes duration, smoking, $\mathrm{BMI}, \mathrm{HbA}_{1 \mathrm{c}}$, $\mathrm{BP}$, lipid profile, renal function, nephropathy and cardiovascular comorbidities, and their associations with LEA in people with type 1 diabetes.

\section{Methods}

Study cohort This study is an observational, population-based cohort study of individuals with type 1 diabetes, 18 years of age or older, in Sweden using data from the Swedish National Diabetes Register (NDR). The cohort was linked to several national Swedish health registers through each unique Swedish personal identification number. These included the National Patient Register (NPR), the Swedish Cause of Death Register and the Longitudinal Integration Database for Health 
Insurance and Labor Market Studies. This study was approved by the regional ethics review board at the University of Gothenburg, Sweden.

The NDR was initiated in 1996 and has been described elsewhere [17]. This register has nationwide coverage and virtually all patients in Sweden with type 1 diabetes are included. The register contains data collected from patient encounters at primary healthcare clinics or hospital outpatient clinics. Collected information includes diabetes-related characteristics and treatment, anthropometrics, risk factors and diabetes-related complications. The epidemiological definition of type 1 diabetes, treatment with insulin and diagnosis at age 30 years or younger, has been adapted to define individuals with type 1 diabetes, and this definition has been estimated to be correct in about $97 \%$ of cases [18]. All people with type 1 diabetes and with at least one registration in the NDR between 1 January 1998 and 2 October 2019 and no previous amputation were included in the study cohort.

The Longitudinal Integration Database for Health Insurance and Labor Market Studies was used for information on country of birth (Sweden or abroad) and level of education stratified into three groups: (1) low (up to 9 years); (2) intermediate (10-12 years); and (3) high (university or college).

The Swedish NPR contains nationwide hospital discharge information since 1987 and is operated by the Swedish National Board of Health and Welfare. Diagnoses in the NPR are registered according to ICD-9 (http://www. icd9data.com/2007/Volume1/default.htm) and ICD-10 (http://apps.who.int/classifications/icd10/browse/2016/en).

Information on time and cause of death was retrieved from the Swedish Cause of Death Register.

Outcome Amputations and comorbidities, including CHD, heart failure, valve disease, stroke, atrial fibrillation and cancer, were collected from the NPR (ICD codes are described in electronic supplementary materials [ESM] Methods section) and mortality data were collected from the Swedish Cause of Death register. Amputation rate was analysed at the anatomical level, minor or major LEA, and at the person level (incidence rate) or limb (first amputation per calendar year).

Exposures Diabetes duration, smoking status, systolic BP (SBP), diastolic BP (DBP), $\mathrm{HbA}_{1 \mathrm{c}}$, creatinine level, albuminuria, LDL-cholesterol and HDL-cholesterol were collected from the NDR. Smoking was defined as current or former (no smoking during the last 3 months). The CKD-EPI equation was used to calculate eGFR, and kidney function was classified according to the National Kidney Foundation [19]. Microalbuminuria was defined as at least two positive results within 1 year and defined as an albumin/creatinine ratio of $3-$ $30 \mathrm{mg} / \mathrm{mmol}(30-300 \mathrm{mg} / \mathrm{g})$ or urinary albumin clearance of 20-200 $\mu \mathrm{g} / \mathrm{min}(20-300 \mathrm{mg} / \mathrm{l})$. Higher ratios defined macroalbuminuria.
Statistical analysis Crude incidence rates were estimated and standardised for age and sex per 1000 person-years. Continuous variables are described using mean \pm SD and median (IQR) values. Categorical variables are presented as $n(\%)$. Poisson regression was used to estimate $95 \%$ CIs for event rates per 1000 person-years. Incidence over time of LEA was evaluated over the following periods: 1998-2001; 2002-2004; 2005-2007; 2008-2010; 2011-2013; 20142016; and 2017-2019. Incidence of LEA was estimated as the unadjusted incidence overall, by sex and age category, and the standardised incidence for age and sex (according to the distribution of the first time period) over time was also determined.

HRs with $95 \%$ CIs, for time to first amputation, time to first major amputation and time to first minor amputation, were estimated with Cox regression models using time-updated means from baseline and onwards (see ESM Methods section). Patients were censored at death or at the date of last data retrieval (2 October 2019). Updated means were calculated for BMI, SBP, DBP, $\mathrm{HbA}_{1 \mathrm{c}}$, LDL-cholesterol, HDLcholesterol and time-updated values for age, smoking, eGFR, albuminuria categories and comorbidities. Model 1 was adjusted for age and sex. Model 2 was further adjusted for education, birth in Sweden, time-updated diabetes duration and baseline comorbidities (CHD, heart failure, valve disease, atrial fibrillation and stroke). Model 3 was further adjusted for time-updated potential risk factors (smoking, $\mathrm{HbA}_{1 \mathrm{c}}, \mathrm{SBP}$ and BMI, unless studied as main effect variable). The gradient of risk was estimated as the change in HR per $1 \mathrm{SD}$ increase or decrease as appropriate.

The longitudinal levels of $\mathrm{HbA}_{1 \mathrm{c}}$ and eGFR over calendar years were estimated using mixed models for repeated measures adjusted for age and sex. Calendar year was analysed as factor variable for estimations presented in figures. For the purpose of describing overall linear increase/ decrease over time, calendar year was analysed as a linear continuous variable in the model.

For tests between groups, Fisher's Exact test was used for dichotomous variables and $t$ test for continuous variables. The time-updated value of each variable was calculated as the mean value of all preceding values and updated when a new value was registered. The last registered value was used until the endpoint.

All analyses were performed using SAS software version 9.4 (SAS Institute, Cary, NC, USA). All tests were two-tailed and conducted at the 0.05 significance level.

\section{Results}

Baseline characteristics Population characteristics of 46,088 individuals with type 1 diabetes included in the study are presented in Table 1. The mean age was 32.5 years (SD 
Table 1 Baseline characteristics of 46,088 people with type 1 diabetes with no previous amputation registered in the NDR 1998-2019

\begin{tabular}{|c|c|c|c|}
\hline Characteristic & $\begin{array}{l}\text { Total } \\
(n=46,088)\end{array}$ & $\begin{array}{l}\text { No amputation } \\
(n=44,569)\end{array}$ & $\begin{array}{l}\text { Any amputation } \\
(n=1519)\end{array}$ \\
\hline \multicolumn{4}{|l|}{ Sex, $n(\%)$} \\
\hline Female & $20,734(45.0)$ & $20,235(45.4)$ & 499 (32.9) \\
\hline \multicolumn{4}{|l|}{ Age, years } \\
\hline Mean \pm SD & $32.5 \pm 14.5$ & $31.9 \pm 14.2$ & $50.1 \pm 12.4$ \\
\hline Median (Q1, Q3) & $28.0(20.0,42.0)$ & $27.0(20.0,40.0)$ & $50.0(41.0,59.0)$ \\
\hline$n$ & 46,088 & 44,569 & 1519 \\
\hline \multicolumn{4}{|l|}{ Age category, $n(\%)$} \\
\hline 18 to $<35$ years & $29,473(63.9)$ & $29,307(65.8)$ & $166(10.9)$ \\
\hline 35 to $<50$ years & 9485 (20.6) & $8943(20.1)$ & $542(35.7)$ \\
\hline 50 to $<65$ years & $5599(12.1)$ & $4984(11.2)$ & $615(40.5)$ \\
\hline$\geq 65$ years & $1531(3.3)$ & $1335(3.0)$ & $196(12.9)$ \\
\hline Born in Sweden, $n(\%)$ & 41,881 (90.9) & $40,442(90.7)$ & $1439(94.7)$ \\
\hline \multicolumn{4}{|c|}{ Education category, $n(\%)$} \\
\hline Low & $11,434(25.9)$ & $10,908(25.6)$ & $526(34.9)$ \\
\hline Mid & $22,817(51.7)$ & $22,067(51.8)$ & $750(49.8)$ \\
\hline High & $9846(22.3)$ & 9615 (22.6) & $231(15.3)$ \\
\hline \multicolumn{4}{|l|}{ Diabetes duration, years } \\
\hline Mean \pm SD & $17.2 \pm 14.5$ & $16.5 \pm 14.2$ & $34.9 \pm 13.0$ \\
\hline Median (Q1, Q3) & $14.0(6.0,26.0)$ & $13.0(6.0,25.0)$ & $35.0(26.0,44.0)$ \\
\hline$n$ & 46,088 & 44,569 & 1519 \\
\hline Smoking ${ }^{\mathrm{a}}, n(\%)$ & $5877(14.2)$ & $5597(14.0)$ & $280(19.4)$ \\
\hline \multicolumn{4}{|l|}{ BMI, $\mathrm{kg} / \mathrm{m}^{2}$} \\
\hline Mean \pm SD & $25.0 \pm 4.3$ & $25.0 \pm 4.3$ & $25.6 \pm 4.4$ \\
\hline Median (Q1, Q3) & $24.4(22.2,27.1)$ & $24.3(22.2,27.0)$ & $25.0(22.6,27.8)$ \\
\hline$n$ & 38,305 & 36,950 & 1355 \\
\hline \multicolumn{4}{|l|}{$\mathrm{HbA}_{1 \mathrm{c}}, \mathrm{mmol} / \mathrm{mol}$} \\
\hline Mean \pm SD & $65.9 \pm 17.0$ & $65.6 \pm 16.9$ & $74.3 \pm 16.1$ \\
\hline Median (Q1, Q3) & $64.0(54.0,75.0)$ & $64.0(54.0,74.0)$ & $73.0(63.0,83.0)$ \\
\hline$n$ & 43,747 & 42,286 & 1461 \\
\hline \multicolumn{4}{|l|}{$\mathrm{HbA}_{1 \mathrm{c}}, \%$} \\
\hline Mean \pm SD & $8.18 \pm 1.55$ & $8.15 \pm 1.55$ & $8.95 \pm 1.47$ \\
\hline Median (Q1, Q3) & $8.01(7.09,9.02)$ & $8.01(7.09,8.92)$ & $8.83(7.92,9.75)$ \\
\hline$n$ & 43,747 & 42,286 & 1461 \\
\hline \multicolumn{4}{|c|}{ 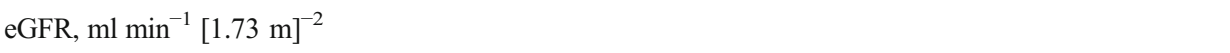 } \\
\hline Mean \pm SD & $109.3 \pm 25.2$ & $110.1 \pm 24.6$ & $73.5 \pm 30.4$ \\
\hline Median (Q1, Q3) & $114.9(96.3,127.5)$ & $115.5(97.1,127.8)$ & $78.9(51.2,95.7)$ \\
\hline$n$ & 22,416 & 21,953 & 463 \\
\hline \multicolumn{4}{|l|}{ Albuminuria, $n(\%)$} \\
\hline None & $29,922(84.2)$ & $29,289(85.6)$ & $633(48.5)$ \\
\hline Microalbuminuria & $3236(9.1)$ & $2958(8.6)$ & $278(21.3)$ \\
\hline Macroalbuminuria & $2381(6.7)$ & $1987(5.8)$ & $394(30.2)$ \\
\hline \multicolumn{4}{|l|}{ LDL (mmol/l) } \\
\hline Mean \pm SD & $2.60 \pm 0.84$ & $2.60 \pm 0.84$ & $2.87 \pm 1.02$ \\
\hline Median (Q1, Q3) & $2.50(2.02,3.08)$ & $2.50(2.02,3.07)$ & $2.76(2.18,3.49)$ \\
\hline$n$ & 18,796 & 18,415 & 381 \\
\hline \multicolumn{4}{|l|}{ HDL, mmol/1 } \\
\hline Mean \pm SD & $1.50 \pm 0.45$ & $1.50 \pm 0.45$ & $1.47 \pm 0.48$ \\
\hline Median (Q1, Q3) & $1.40(1.20,1.70)$ & $1.40(1.20,1.70)$ & $1.40(1.10,1.70)$ \\
\hline
\end{tabular}


Table 1 (continued)

\begin{tabular}{llll}
\hline Characteristic & $\begin{array}{l}\text { Total } \\
(n=46,088)\end{array}$ & $\begin{array}{l}\text { No amputation } \\
(n=44,569)\end{array}$ & $\begin{array}{l}\text { Any amputation } \\
(n=1519)\end{array}$ \\
\hline$n$ & 19,014 & 18,630 & 384 \\
SBP, mmHg & $125.3 \pm 16.5$ & $124.7 \pm 16.1$ & $141.1 \pm 19.4$ \\
$\quad$ Mean \pm SD & $120.0(115.0,135.0)$ & $120.0(115.0,132.0)$ & $140.0(130.0,150.0)$ \\
Median (Q1, Q3) & 41,583 & 40,134 & 1449 \\
$n$ & & & $76.5 \pm 10.1$ \\
DBP, mmHg & $73.3 \pm 9.2$ & $73.1 \pm 9.1$ & $80.0(70.0,80.0)$ \\
$\quad$ Mean \pm SD & $73.0(70.0,80.0)$ & $72.0(69.0,80.0)$ & 1445 \\
$\quad$ Median (Q1, Q3) & 41,484 & 40,039 & $284(18.7)$ \\
$n$ & $1804(3.9)$ & $1520(3.4)$ & $110(7.2)$ \\
CHD (I20-I25), $n(\%)$ & $592(1.3)$ & $482(1.1)$ & $16(1.1)$ \\
Heart failure (I50), $n(\%)$ & $223(0.5)$ & $207(0.5)$ & $117(7.7)$ \\
Valve disease (I05-I09,I34-I36), $n(\%)$ & $516(1.2)$ & $59(3.9)$ \\
Stroke (I61-I64), $n(\%)$ & $633(1.4)$ & $717(1.6)$ & $40(2.6)$ \\
Cancer (C00-C97), $n(\%)$ & $776(1.7)$ & $245(0.5)$ & \\
Atrial fibrillation (I48), $n(\%)$ & $285(0.6)$ & & \\
\hline
\end{tabular}

For cardiovascular comorbidities ICD-10 codes are presented in parentheses

${ }^{\mathrm{a}}$ Missing data excluded from analyses

$14.5)$ and $45 \%$ were women. The mean duration of diabetes was 17.2 years (SD 14.5), mean $\mathrm{HbA}_{1 \mathrm{c}}$ was $65.9 \mathrm{mmol} / \mathrm{mol}$ (SD 17) $(8.2 \%$ [SD 1.6]) and $14.2 \%$ were smokers. During follow-up 1519 (3.3\%) participants underwent an amputation, $609(1.3 \%)$ a minor amputation, $585(1.3 \%)$ a major amputation and $325(0.7 \%)$ both minor and major amputations. Participants with any amputations were older (mean 50.1 years [SD 12.4]), had longer duration of diabetes (34.9 years [SD $13]$ ), and included a higher proportion of men (67.1\%) and smokers $(19.4 \%)$. Participants with any amputation presented with increased burden of cardiovascular comorbidities and risk factors for CVDs compared with those with no amputation. A similar distribution of risk factor burden was also noted in the groups with minor and major amputations when analysed separately (data not shown).

\section{Changes in risk factors and incidences of LEA over time} (1998-2019) The crude incidence of any LEA was 2.7 (95\% CI 2.6, 2.9) per 1000 person-years during the median followup of 12.4 years (IQR 6.6, 18.0) (ESM Table 1). The age- and sex-adjusted incidence of any LEA decreased significantly over time from 1998 to 2019, with a clear drop during the period 2014-2019 (Fig. 1a). The standardised incidence per 1000 person-years was $2.84(95 \%$ CI 2.32, 3.36) in 19982001, 2.81 (95\% CI 2.44, 3.18) in 2005-2007, 2.45 (95\% CI $2.15,2.75)$ in $2011-2013$ and 1.64 (95\% CI 1.38, 1.90) in 2017-2019 (ESM Table 2). During this time, glycaemic control, estimated by $\mathrm{HbA}_{1 \mathrm{c}}$, was significantly worse for patients with LEA than those without LEA and improved over time for those without LEA, with a mean reduction of $0.02 \%$
(95\% CI 0.02, 0.02) per year (Fig. 1b and ESM Table 3). Renal function, estimated by age- and sex-adjusted eGFR, was worse in participants experiencing LEA and only improved over time for participants without LEA, with a mean improvement of $0.23(95 \% \mathrm{CI} 0.21,0.23) \mathrm{ml} \mathrm{min}^{-1}[1.73 \mathrm{~m}]^{-2}$ per year (Fig. 1c and ESM Table 4).

Effect of potential risk factors on risk for amputation Table 2 shows results from analyses studying time to amputation through time-updated potential risk factors in the fully adjusted Cox regression model 3. The Cox regression model for time-updated variables for models 1 and 2 are presented in ESM Table 5. Older age was associated with an increased risk of any amputation, HR 1.04 (95\% CI 1.03, 1.04; $p<0.0001)$ per year. Moreover, the Cox regression model revealed that significant risk factors for amputations were smoking (HR 1.36 [95\% CI 1.17, 1.58]; $p<0.0001)$ and comorbidities including heart failure (HR 3.28 [95\% CI 2.86, 3.77]; $p<0.0001$ ), CHD (HR 2.26 [95\% CI 2.00, 2.55]; $p<0.0001)$, stroke (HR 2.12 [95\% CI 1.84, 2.45]; $p<0.0001$ ), atrial fibrillation (HR 1.91 [95\% CI 1.59, 2.29]; $p<0.0001$ ) and valve disease (HR 1.89 [95\% CI 1.51, 2.38]; $p<0.0001)$.

Higher $\mathrm{HbA}_{1 \mathrm{c}}$ levels were strongly associated with increased risk of amputation in the fully adjusted model, with an HR of 1.69 (95\% CI 1.63, 1.76; $p<0.0001)$ per each $10 \mathrm{mmol} / \mathrm{mol}(\sim 1 \%)$ increase. This risk increased monotonically with higher $\mathrm{HbA}_{1 \mathrm{c}}$ and at levels $>82 \mathrm{mmol} / \mathrm{mol}(\sim 9.6 \%)$ the HR was 11.97 (95\% CI 9.13, 15.70; $p<0.0001)$ (Fig. 2 and ESM Table 6). 


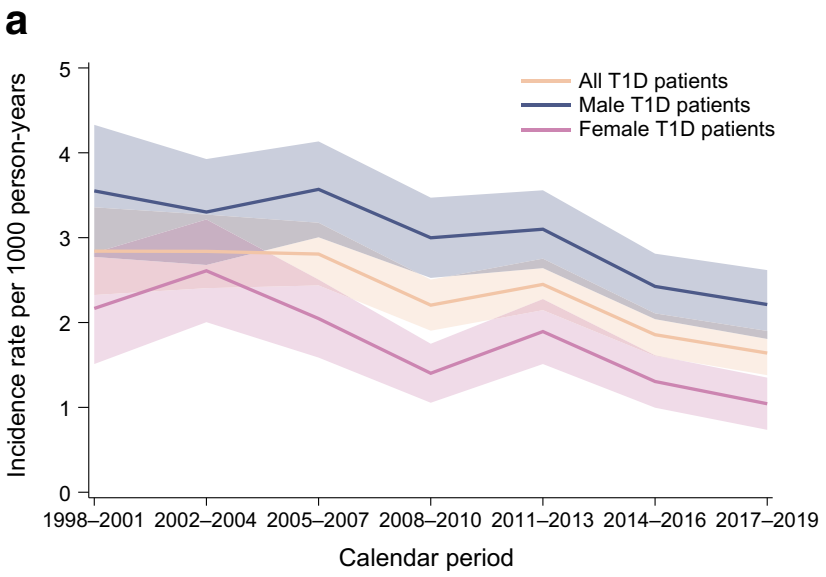

b

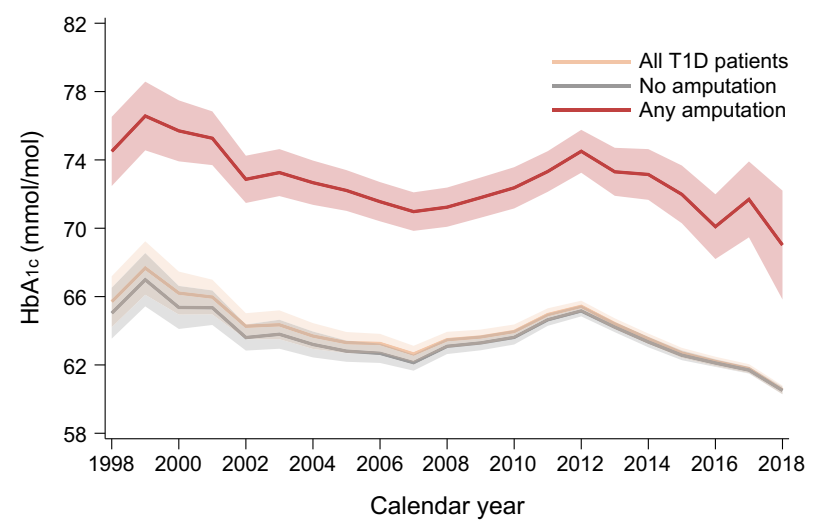

C

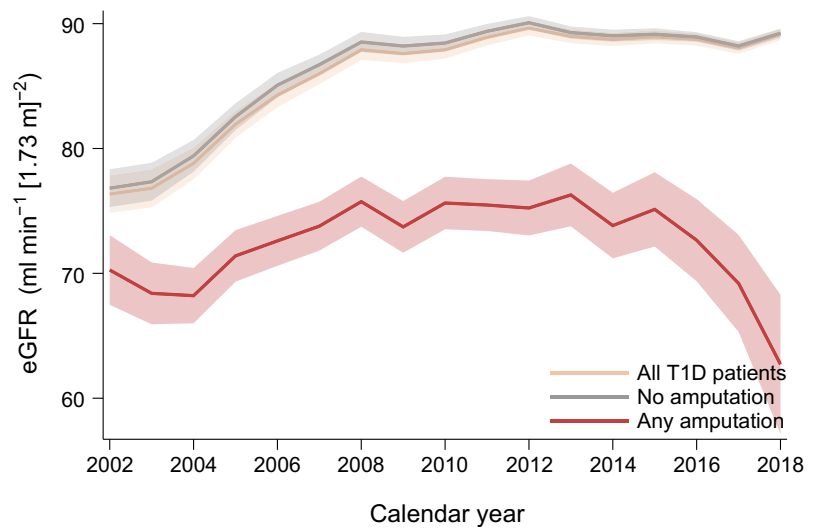

Fig. 1 (a) Standardised incidence rates with 95\% CIs for any amputation in people with type 1 diabetes over time. (b) Mean $\mathrm{HbA}_{1 \mathrm{c}}$ with $95 \% \mathrm{CIs}$ in people with type 1 diabetes and in those with type 1 diabetes and amputation. (c) Mean eGFR with 95\% CIs in people with type 1 diabetes and in those with type 1 diabetes and amputation. T1D, type 1 diabetes

Renal dysfunction was associated with increased risk of amputation (HR 1.24 [95\% CI 1.21, 1.26], $p<0.0001$ ) per $10 \mathrm{ml} \mathrm{min}^{-1}[1.73 \mathrm{~m}]^{-2}$ decrease in eGFR) and related to CKD stages (Table 2, Fig. 2). At eGFR $<30 \mathrm{ml} \mathrm{min}^{-1}$ $[1.73 \mathrm{~m}]^{-2}$ the HR was $5.78(95 \%$ CI $4.85,6.90 ; p<0.0001)$ compared with eGFR $\geq 90 \mathrm{ml} \mathrm{min}{ }^{-1}[1.73 \mathrm{~m}]^{-2}$ in the fully adjusted model.

The risk of amputation was also related to higher BP, with an HR of 1.28 (95\% CI 1.24, 1.33; $p<0.0001)$ per each $10 \mathrm{mmHg}$ increase in SBP and 1.18 (95\% CI 1.14, 1.23; $p<0.0001)$ per each $5 \mathrm{mmHg}$ increase in DBP. This risk increased monotonically when SBP surpassed $130 \mathrm{mmHg}$ in the fully adjusted model as seen in Fig. 2.

Overall, increasing BMI had a protective effect on the risk of any amputation, with an HR of 0.92 (95\% CI 0.86, 0.99; $p=0.018$ ) per $5 \mathrm{~kg} / \mathrm{m}^{2}$ (Table 2). Comparing risk related to different categories of BMI, the risk of amputation associated with being underweight (BMI $<18.5 \mathrm{~kg} / \mathrm{m}^{2}$ ) was increased while being overweight had a small protective effect and obesity had no significant effect on the risk of any amputation (Fig. 2).

LDL-cholesterol levels were not significantly related to the risk of amputation; however, increasing HDL-cholesterol concentration had a protective effect (HR 0.61 [95\% CI $0.52,0.71] ; p<0.0001$, per each $1 \mathrm{mmol} / \mathrm{l}$ increase) (Table 2).

Similar results were found in the Cox regression models separately analysing minor and major amputations; exceptions were increasing BMI (no protective effect when analysing risk factors for major amputation) and smoking (not significant as a risk factor for minor amputations) (ESM Tables 7, 8).

Gradient of risk per 1 SD Gradient of risk per SD was estimated to compare the relative influence of the various risk factors on amputations. The standardised HR per $1 \mathrm{SD}$ was highest for macroalbuminuria, followed by $\mathrm{HbA}_{1 \mathrm{c}}$, age, decreased eGFR, microalbuminuria, male sex, SBP, DBP, cardiovascular comorbidities and smoking (Table 2).

\section{Discussion}

In this nationwide observational cohort study, the risk of LEA was substantially reduced over time and the incidence was more than 40\% lower during 2017-2019 than during 19982001. The major reduction occurred during 2014-2019 along with clear improvements in glycaemic control and renal function, which were the most prominent risk factors related to LEA.

Older age, male sex, cardiovascular comorbidities, renal dysfunction, increased $\mathrm{HbA}_{1 \mathrm{c}}$, hypertension and smoking were risk factors for amputation in people with type 1 diabetes. There was no statistically significant association between increased LDL-cholesterol concentrations and risk for amputation, while increased HDL concentrations were shown to be protective. The association between risk of amputation and BMI showed no associated monotonic change but being underweight was clearly related to increased risk. 
Table 2 Time-updated potential risk factors and their association to any amputation in people with type 1 diabetes analysed by Cox regression

\begin{tabular}{|c|c|c|c|c|c|c|}
\hline Variable & No. (\%) of events & No. (\%) of patients ${ }^{\mathrm{a}}$ & $\mathrm{HR}(95 \% \mathrm{CI})$ & SD & $\begin{array}{l}\text { Standardised HR per } \\
1 \text { SD increase }(95 \% \mathrm{CI})\end{array}$ & $p$ value \\
\hline Age & $1421(93.5)$ & $42,270(91.7)$ & & & & \\
\hline Risk by 1 year increase & & & $1.04(1.03,1.04)$ & 15.24 & $1.72(1.54,1.92)$ & $<0.0001$ \\
\hline Sex & $1421(93.5)$ & $42,270(91.7)$ & & & & \\
\hline Female vs male & & & $0.51(0.46,0.57)$ & 0.5 & $0.72(0.68,0.76)$ & $<0.0001$ \\
\hline Smoking & $1421(93.5)$ & $42,270(91.7)$ & & & & \\
\hline Risk for yes vs no & & & $1.36(1.17,1.58)$ & 0.32 & $1.10(1.05,1.16)$ & $<0.0001$ \\
\hline BMI, $\mathrm{kg} / \mathrm{m}^{2}$ & $1421(93.5)$ & $42,270(91.7)$ & & & & \\
\hline Risk by $5 \mathrm{mg} / \mathrm{kg}^{2}$ increase & & & $0.92(0.86,0.99)$ & 4.02 & $0.94(0.89,0.99)$ & 0.018 \\
\hline $\mathrm{HbA}_{1 \mathrm{c}}$ & $1421(93.5)$ & $42,270(91.7)$ & & & & \\
\hline Risk by $10 \mathrm{mmol} / \mathrm{mol}$ increase & & & $1.69(1.63,1.76)$ & 12.86 & $1.97(1.88,2.06)$ & $<0.0001$ \\
\hline Risk by $1 \%$ increase & & & $1.78(1.71,1.85)$ & 1.18 & $1.97(1.88,2.06)$ & $<0.0001$ \\
\hline eGFR, & $1228(80.8)$ & $40,841(88.6)$ & & & & \\
\hline 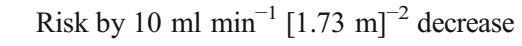 & & & $1.24(1.21,1.26)$ & 24.70 & $1.69(1.61,1.77)$ & $<0.0001$ \\
\hline Albuminuria category & $1397(92.0)$ & $41,455(89.9)$ & & & & \\
\hline \multicolumn{7}{|l|}{ Normoalbuminuria } \\
\hline Microalbuminuria & & & $1.95(1.71,2.23)$ & 0.56 & $1.46(1.35,1.57)$ & $<0.0001$ \\
\hline Macroalbuminuria & & & $3.57(3.12,4.09)$ & 0.56 & $2.05(1.90,2.21)$ & $<0.0001$ \\
\hline LDL-cholesterol, mmol/l & $1178(77.6)$ & $40,235(87.3)$ & & & & \\
\hline Risk by $1 \mathrm{mmol} / \mathrm{l}$ increase & & & $0.95(0.88,1.04)$ & 0.67 & $0.97(0.92,1.03)$ & 0.27 \\
\hline HDL-cholesterol, mmol/1 & $1170(77.0)$ & $40,029(86.9)$ & & & & \\
\hline Risk by $1 \mathrm{mmol} / \mathrm{l}$ increase & & & $0.61(0.52,0.71)$ & 0.43 & $0.81(0.76,0.86)$ & $<0.0001$ \\
\hline $\mathrm{SBP}, \mathrm{mmHg}$ & $1421(93.5)$ & $42,270(91.7)$ & & & & \\
\hline Risk by $10 \mathrm{mmHg}$ increase & & & $1.28(1.24,1.33)$ & 12.84 & $1.38(1.31,1.44)$ & $<0.0001$ \\
\hline $\mathrm{DBP}, \mathrm{mmHg}$ & $1420(93.5)$ & $42,261(91.7)$ & & & & \\
\hline Risk by $5 \mathrm{mmHg}$ increase & & & $1.18(1.14,1.23)$ & 6.69 & $1.25(1.19,1.31)$ & $<0.0001$ \\
\hline CHD (I20-I25) & $1421(93.5)$ & $42,270(91.7)$ & & & & \\
\hline Risk for yes vs no & & & $2.26(2.00,2.55)$ & 0.27 & $1.25(1.21,1.29)$ & $<0.0001$ \\
\hline Heart failure (I50) & $1421(93.5)$ & $42,270(91.7)$ & & & & \\
\hline Risk for yes vs no & & & $3.28(2.86,3.77)$ & 0.16 & $1.21(1.18,1.23)$ & $<0.0001$ \\
\hline Valve disease (I05-I09,I34-I36) & $1421(93.5)$ & $42,270(91.7)$ & & & & \\
\hline Risk for yes vs no & & & $1.89(1.51,2.38)$ & 0.11 & $1.07(1.04,1.10)$ & $<0.0001$ \\
\hline Atrial fibrillation (I48) & $1421(93.5)$ & $42,270(91.7)$ & & & & \\
\hline Risk for yes vs no & & & $1.91(1.59,2.29)$ & 0.13 & $1.09(1.06,1.11)$ & $<0.0001$ \\
\hline Stroke (I61-I64) & $1421(93.5)$ & $42,270(91.7)$ & & & & \\
\hline Risk for yes vs no & & & $2.12(1.84,2.45)$ & 0.16 & $1.13(1.10,1.16)$ & $<0.0001$ \\
\hline Cancer (C00-C97) & $1421(93.5)$ & $42,270(91.7)$ & & & & \\
\hline Risk for yes vs no & & & $1.23(1.04,1.45)$ & 0.20 & $1.04(1.01,1.08)$ & 0.018 \\
\hline
\end{tabular}

Table shows risk calculated using model 3, adjusted for time-updated age, sex, education, born in Sweden, time-updated diabetes duration and baseline comorbidities, time-updated variables of smoking, $\mathrm{HbA}_{1 \mathrm{c}}$, $\mathrm{SBP}$, BMI (unless main effect variable)

${ }^{\mathrm{a}}$ The analysis for sex and time-updated analyses for age, comorbidities, smoking, $\mathrm{HbA}_{1 \mathrm{c}}$, SBP and $\mathrm{BMI}$ included the same patients comprising the complete case population, $n=42,770$. For the analyses of other time-updated variables patients with no follow-up data for the corresponding main effect variable were additionally excluded

The association between amputation and person-level risk factors in individuals with diabetes has been studied but most studies have been in populations with type 2 diabetes, mixed populations or in very high-risk populations such as people with established foot ulcers [11, 13-15, 20-23]. Sahakyan et al described heavy smoking, hypertension and higher $\mathrm{HbA}_{1 \mathrm{c}}$ to be associated with increased risk of amputation in people with type 1 diabetes [16]. 
Fig. 2 Potential time-updated risk factors by categories and their association with any amputation in people with type 1 diabetes

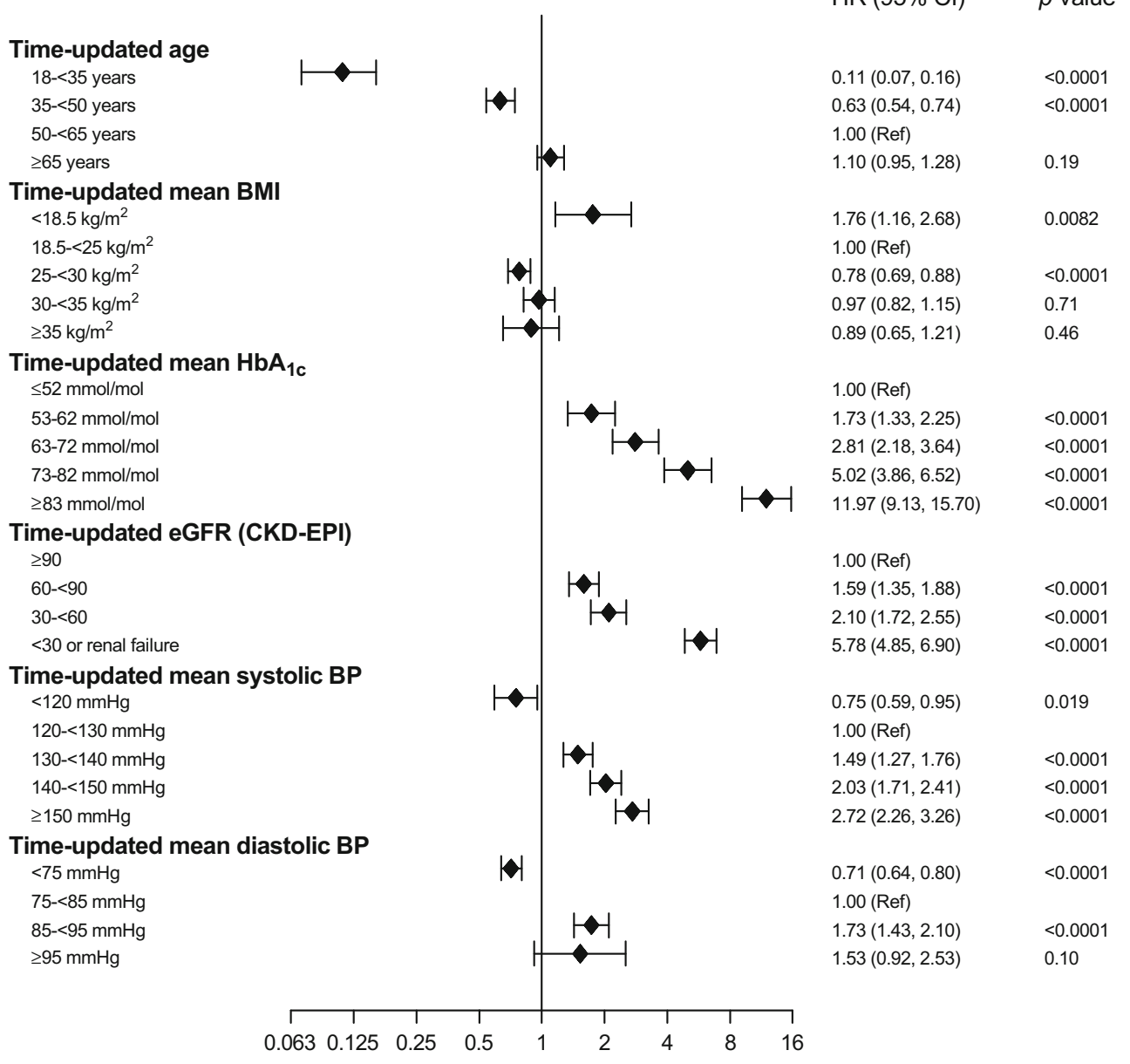

In previous evaluations of incidences of LEA over time no clear reductions were found until 2013, when a 40-fold excess risk compared with the general population was reported [5]. We found that amputation decreased significantly over time, especially from 2014 onwards, along with improved glycaemic control and fewer renal complications. These changes are possibly related to an increased focus on risk factor management, advanced treatments to optimise glycaemic control, and further enhancements in the armamentarium of multidisciplinary diabetes foot clinics, including an increased use of invasive arterial reperfusion.

Diabetes micro- and macroangiopathy are accelerated by local vascular inflammation, hyperlipidaemia, hyperglycaemia and hypertension and lead to ischaemia and loss of protective sensibility, which are risk factors for LEA $[1,6,7]$.

In type 1 diabetes, hyperglycaemia is a risk factor for CVD and the association with LEA has been recognised [11, 17, 24, $25]$. We found that every $1 \%$ increase in $\mathrm{HbA}_{1 \mathrm{c}}$ was associated with a $78 \%$ increased risk of amputation. An $\mathrm{HbA}_{1 \mathrm{c}}$ level $>72 \mathrm{mmol} / \mathrm{mol}(8.2 \%)$ was associated with a fivefold LEA risk compared with $\mathrm{HbA}_{1 \mathrm{c}}<53 \mathrm{mmol} / \mathrm{mol}$ (7.0\%). The impairment of ulcer healing and acceleration of arteriosclerotic disease may be mechanisms by which hyperglycaemia increase the amputation risk [1, 6, 7].

Interestingly, in our study, amputation rates were lower in the overweight population than in those with normal BMI. This finding might be disturbed by increased risk and more severe comorbidity in those in the lower normal BMI range. This is supported by the significantly higher LEA risk in underweight individuals, a result consistent with earlier studies on BMI and CVD in individuals with type 1 diabetes [26]. Neither obesity nor severe obesity was associated with an increased LEA risk when compared with normal weight.

Hypertension and the closely related diabetes renal dysfunction were both associated with increased risk of amputation. Diabetes renal disease is caused by microangiopathy and usually indicates prolonged antecedent duration of hyperglycaemia solely or in combination with hypertension [27]. Our results support the importance of glycaemic and BP control in order to preserve renal function and reduce the risk of neuropathy and improve healing of diabetic foot ulcers.

Smoking and lower concentrations of HDL-cholesterol increased the risk of amputation, although the impact on risk was minor. However, LDL-cholesterol concentration did not have an effect on the risk of amputation, probably explained 
by hyperlipidaemia acting indirectly through other LEA risk factors such as renal dysfunction and increased BP.

The current study has several implications since the relatively similar incidence of LEA until 2013 is shown to decrease dramatically during 2014-2019. LEA is a large burden for the affected individual; it is strongly related to reduced quality of life, influences work possibilities for many people and often leads to sick-leave from work [4, 28, 29]. In addition, LEA has a significant impact on immediate and long-term healthcare costs [2]. The improved prognosis for amputations, renal complications and glycaemic control over time indicates a breakthrough in type 1 diabetes care; the prognosis for CVD and mortality will also likely improve, and this will be evaluated in future projects. The strong association between glycaemic control and amputations, as shown in this study, when compared with cardiovascular and renal disease suggests that through significantly improved glycaemic control amputations will probably decrease [17, $24,25]$. Our study indicates a shift in the era of diabetes probably due to the more extensive use of modern equipment in glucose-lowering therapy, such as advanced insulin pumps and continuous glucose monitoring devices [30,31].

Optimisation of other risk factors, including blood lipids and $\mathrm{BP}$ levels, although having less importance than $\mathrm{HbA}_{1 \mathrm{c}}$ as shown here, will further improve prognosis. Generally, there are long time-lags, termed metabolic memory or legacy effects, between optimisation of glycaemic control and complications [32]. Many older diabetic individuals today have had insufficient glucose treatment earlier in life (e.g. only basal insulin therapy with coexisting very high glucose levels). Hence, the current beneficial trends over time seen for LEA will probably be even stronger over the coming years.

This study includes a large number of individuals with type 1 diabetes in Sweden and is based on registers with nationwide coverage of the Swedish population. Data retrieved from the registers also includes information on the most common and updated cardiovascular risk factors, enabling multivariate analysis and estimates on the impact of exposure to each risk factor. The relationship between the risk factors of diabetes micro- and macroangiopathy is complex and therefore analysis of the different potential risk factors for amputations was performed with adjustment for other potential risk factors [6]. The cohort was contemporary, evaluated until 2 October 2019.

Limitations include the lack of information on certain limbspecific risk factors such as neuropathy, reduced circulation, or deformities that affect the risk of amputation. Regression models were created to estimate the risk associated with each risk factor; however, due to the design of this study residual confounding cannot be excluded and a causal relationship between the potential risk factor and outcome cannot be established.

In conclusion, prognosis improved considerably over time during the last decade regarding LEAs in people with type 1 diabetes, while glycaemic control and renal function improved. The strongest risk factors for amputations in people with type 1 diabetes were renal dysfunction and increased $\mathrm{HbA}_{1 \mathrm{c}}$, followed by older age, hypertension, cardiovascular comorbidities and smoking. We found no significant association between LEA and concentrations of LDL-cholesterol but found a protective effect with increased HDL-cholesterol levels. Increased BMI levels are probably not a risk factor for amputation but being underweight was strongly associated with an increased risk of LEAs.

Supplementary Information The online version contains peer-reviewed but unedited supplementary material available at https://doi.org/10.1007/ s00125-021-05550-z.

Acknowledgements We thank all clinicians involved in the care of the individuals with type 1 diabetes for data collection and we also thank the staff at the NDR.

Data availability The data that support the findings of this study are available from the National Board of Health Welfare in Sweden and from The Swedish NDR. Restrictions apply to the availability of these data, which were used under license for the current study, and according to Swedish legislation are not publicly available.

Funding Open access funding provided by University of Gothenburg. This study was financed by grants from the Swedish state under an agreement between the Swedish Government and the County Councils Concerning Economic Support of Research and Education of Doctors, Region Västra Götaland, grants from the Novo Nordisk foundation and grants from the Swedish Foundation for Rehabilitation and medical research (FRF). The funders had no role in collecting data, study design, interpretation of data or the decision to submit the manuscript for publication.

Authors' relationships and activities MLi has been a consultant or received honoraria from Astra Zeneca, Boehringer-Ingelheim Eli Lilly, MSD and Novo Nordisk and received research grants from DexCom and Novo Nordisk. MLo has been a consultant or received honoraria from Abbott, Amgen, AstraZeneca, Boehringer-Ingelheim, Eli Lilly, Merck, Novo Nordisk and Sanofi. All other authors declare that there are no relationships or activities that might bias, or be perceived to bias, their work.

Contribution statement MLi, MLo, AP, AMS, AFO and SH contributed to the conception and design of the study. MLi, SH and AMS were responsible for acquisition of the data. $\mathrm{MLi}, \mathrm{AP}, \mathrm{SH}, \mathrm{HW}$ and $\mathrm{AFO}$ participated in the analysis and interpretation of data. The manuscript was drafted by SH. MLi, MLo, AP, SH, HW, AMS and AFO participated in critical revision of the paper and gave final approval to submit the manuscript for publication. SH, the corresponding author, had full access to all the data in the study and takes responsibility for the integrity of the data and the accuracy of the data analysis.

Open Access This article is licensed under a Creative Commons Attribution 4.0 International License, which permits use, sharing, adaptation, distribution and reproduction in any medium or format, as long as 
you give appropriate credit to the original author(s) and the source, provide a link to the Creative Commons licence, and indicate if changes were made. The images or other third party material in this article are included in the article's Creative Commons licence, unless indicated otherwise in a credit line to the material. If material is not included in the article's Creative Commons licence and your intended use is not permitted by statutory regulation or exceeds the permitted use, you will need to obtain permission directly from the copyright holder. To view a copy of this licence, visit http://creativecommons.org/licenses/by/4.0/.

\section{References}

1. Lepäntalo M, Apelqvist J, Setacci C et al (2011) Chapter V: Diabetic Foot. Eur J Vasc Endovasc Surg 42:S60-S74. https:// doi.org/10.1016/S1078-5884(11)60012-9

2. Alva ML, Gray A, Mihaylova B, Leal J, Holman RR (2015) The impact of diabetes-related complications on healthcare costs: new results from the UKPDS (UKPDS 84). Diabet Med 32(4):459-466. https://doi.org/10.1111/dme.12647

3. Zhang Y, Lazzarini PA, McPhail SM, van Netten JJ, Armstrong DG, Pacella RE (2020) Global Disability Burdens of DiabetesRelated Lower-Extremity Complications in 1990 and 2016. Diabetes Care 43(5):964-974. https://doi.org/10.2337/dc19-1614

4. Barg FK, Cronholm PF, Easley EE et al (2017) A qualitative study of the experience of lower extremity wounds and amputations among people with diabetes in Philadelphia. Wound Repair Regen 25(5):864-870. https://doi.org/10.1111/wrr.12593

5. Olafsdottir AF, Svensson AM, Pivodic A et al (2019) Excess risk of lower extremity amputations in people with type 1 diabetes compared with the general population: amputations and type 1 diabetes. BMJ Open Diabetes Res Care 7(1):e000602. https://doi. org/10.1136/bmjdrc-2018-000602

6. Madonna R, Pieragostino D, Balistreri CR et al (2018) Diabetic macroangiopathy: Pathogenetic insights and novel therapeutic approaches with focus on high glucose-mediated vascular damage. Vasc Pharmacol S1537-1891(17):30322-30321

7. Madonna R, Balistreri CR, Geng YJ, De Caterina R (2017) Diabetic microangiopathy: Pathogenetic insights and novel therapeutic approaches. Vasc Pharmacol 90:1-7. https://doi.org/10. 1016/j.vph.2017.01.004

8. Singh N, Armstrong DG, Lipsky BA (2005) Preventing Foot Ulcers in Patients With Diabetes. Jama. 293(2):217-228. https:// doi.org/10.1001/jama.293.2.217

9. Apelqvist J, Elgzyri T, Larsson J, Löndahl M, Nyberg P, Thörne J (2011) Factors related to outcome of neuroischemic/ischemic foot ulcer in diabetic patients. J Vasc Surg 53(6):1582-8.e2. https://doi. org/10.1016/j.jvs.2011.02.006

10. Musuuza J, Sutherland BL, Kurter S, Balasubramanian P, Bartels CM, Brennan MB (2020) A systematic review of multidisciplinary teams to reduce major amputations for patients with diabetic foot ulcers. J Vasc Surg 71(4):1433-46. e3. https://doi.org/10.1016/j. jvs.2019.08.244

11. Adler AI, Erqou S, Lima TA, Robinson AH (2010) Association between glycated haemoglobin and the risk of lower extremity amputation in patients with diabetes mellitus-review and meta-analysis. Diabetologia. 53(5):840-849. https://doi.org/10.1007/s00125009-1638-7

12. Otte J, van Netten JJ, Woittiez A-JJ (2015) The association of chronic kidney disease and dialysis treatment with foot ulceration and major amputation. J Vasc Surg 62(2):406-411. https://doi.org/ 10.1016/j.jvs.2015.02.051

13. Boyko EJ, Seelig AD, Ahroni JH (2018) Limb- and Person-Level Risk Factors for Lower-Limb Amputation in the Prospective Seattle
Diabetic Foot Study. Diabetes Care 41(4):891-898. https://doi.org/ $10.2337 / \mathrm{dc} 17-2210$

14. Stratton IM, Adler AI, Neil HA et al (2000) Association of glycaemia with macrovascular and microvascular complications of type 2 diabetes (UKPDS 35): prospective observational study. BMJ (Clin Res Ed) 321(7258):405-412. https://doi.org/10.1136/ bmj.321.7258.405

15. Zhou Z-Y, Liu Y-K, Chen H-L, Yang H-L, Liu F (2015) HbAlc and Lower Extremity Amputation Risk in Patients With Diabetes:A Meta-Analysis. Int J Low Extrem Wounds 14(2):168-177. https:// doi.org/10.1177/1534734615593190

16. Sahakyan K, Klein BE, Lee KE, Myers CE, Klein R (2011) The 25year cumulative incidence of lower extremity amputations in people with type 1 diabetes. Diabetes Care 34(3):649-651. https://doi.org/ $10.2337 / \mathrm{dc} 10-1712$

17. Lind M, Bounias I, Olsson M, Gudbjörnsdottir S, Svensson AM, Rosengren A (2011) Glycaemic control and incidence of heart failure in 20,985 patients with type 1 diabetes: an observational study. Lancet (London, England) 378(9786):140-146

18. Eeg-Olofsson K, Cederholm J, Nilsson PM et al (2010) Glycemic control and cardiovascular disease in 7,454 patients with type 1 diabetes: an observational study from the Swedish National Diabetes Register (NDR). Diabetes Care 33(7):1640-1646. https://doi.org/10.2337/dc10-0398

19. Levey AS, Eckardt KU, Tsukamoto $Y$ et al (2005) Definition and classification of chronic kidney disease: a position statement from Kidney Disease: Improving Global Outcomes (KDIGO). Kidney Int 67(6):2089-2100. https://doi.org/10.1111/j.1523-1755.2005.00365.x

20. Sohn MW, Budiman-Mak E, Oh EH et al (2012) Obesity paradox in amputation risk among nonelderly diabetic men. Obesity (Silver Spring, Md) 20(2):460-462. https://doi.org/10.1038/oby.2011.301

21. Callaghan BC, Feldman E, Liu J et al (2011) Triglycerides and amputation risk in patients with diabetes: ten-year follow-up in the DISTANCE study. Diabetes Care 34(3):635-640. https://doi. org/10.2337/dc10-0878

22. Zubair M, Malik A, Ahmad J (2012) Incidence, risk factors for amputation among patients with diabetic foot ulcer in a North Indian tertiary care hospital. Foot (Edinburgh, Scotland) 22(1):24-30

23. Ghanassia E, Villon L, Thuan dit Dieudonné J-F, Boegner C, Avignon A, Sultan A (2008) Long-Term Outcome and Disability of Diabetic Patients Hospitalized for Diabetic Foot Ulcers. Diabetes Care 31(7):1288. https://doi.org/10.2337/dc07-2145

24. Matuleviciene-Anangen V, Rosengren A, Svensson AM et al (2017) Glycaemic control and excess risk of major coronary events in persons with type 1 diabetes. Heart 103(21):1687-1695. https:// doi.org/10.1136/heartjnl-2016-311050

25. Hallstrom S, Pivodic A, Rosengren A, Olafsdottir AF, Svensson AM, Lind M (2019) Risk Factors for Atrial Fibrillation in People With Type 1 Diabetes: An Observational Cohort Study of 36,258 Patients From the Swedish National Diabetes Registry. Diabetes Care 42(8):1530-1538. https://doi.org/10.2337/dc18-2457

26. Vestberg D, Rosengren A, Eeg-Olofsson K et al (2018) Body mass index as a risk factor for coronary events and mortality in patients with type 1 diabetes. Open Heart 5(1):e000727. https://doi.org/10. 1136/openhrt-2017-000727

27. Shahbazian H, Rezaii I (2013) Diabetic kidney disease; review of the current knowledge. J Renal Inj Prev 2(2):73. https://doi.org/10. 12861/jrip.2013.24

28. Hayes A, Arima H, Woodward M et al (2016) Changes in Quality of Life Associated with Complications of Diabetes: Results from the ADVANCE Study. Value Health 19(1):36-41. https://doi.org/ 10.1016/j.jval.2015.10.010

29. Whyte AS, Carroll LJ (2002) A preliminary examination of the relationship between employment, pain and disability in an amputee population. Disabil Rehabil 24(9):462-470 
30. Lind M, Polonsky W, Hirsch IB et al (2017) Continuous Glucose Monitoring vs Conventional Therapy for Glycemic Control in Adults With Type 1 Diabetes Treated With Multiple Daily Insulin Injections: The GOLD Randomized Clinical Trial. JAMA 317(4): 379-387. https://doi.org/10.1001/jama.2016.19976

31. Karges B, Schwandt A, Heidtmann B et al (2017) Association of Insulin Pump Therapy vs Insulin Injection Therapy With Severe Hypoglycemia, Ketoacidosis, and Glycemic Control Among Children, Adolescents, and Young Adults With Type 1 Diabetes.
Jama. JAMA 318(14):1358-1366. https://doi.org/10.1001/jama. 2017.13994

32. Ceriello A, Ihnat MA, Thorpe JE (2009) The "Metabolic Memory": Is More Than Just Tight Glucose Control Necessary to Prevent Diabetic Complications? J Clin Endocrinol Metab 94(2):410-415. https://doi.org/10.1210/jc.2008-1824

Publisher's note Springer Nature remains neutral with regard to jurisdictional claims in published maps and institutional affiliations. 